\title{
WEEKLY VARIATIONS OF BIOMECHANICAL LOAD VARIABLES IN PROFESSIONAL SOCCER PLAYERS: COMPARISONS BETWEEN PLAYING POSITIONS
}

original paper

( ) University School of Physical Education in Wroclaw

DOI: https://doi.org/10.5114/hm.2021.100321

\section{UDAY CH. HASAN $^{1}$, RUI SILVA ${ }^{2}$, FILIPE MANUEL CLEMENTE ${ }^{2,3}$}

${ }^{1}$ Department of Physical Education and Sports Sciences, Al-Kitab University, Kirkuk, Iraq

${ }^{2}$ Escola Superior Desporto e Lazer, Instituto Politécnico de Viana do Castelo, Viana do Castelo, Portugal

${ }^{3}$ Instituto de Telecomunicações, Delegação da Covilhã, Lisbon, Portugal

\section{ABSTRACT}

Purpose. The purpose of the present study was fourfold: (i) to describe the weekly variations of acute external load measures during a professional soccer season; (ii) to analyse the variability of external load measures within weeks; (iii) to analyse the acute:chronic workload ratio of players during the process; and (iv) to analyse the differences of external load measures between playing positions.

Methods. Twenty professional soccer players (age: $24.9 \pm 3.5$ years; body mass: $71.6 \pm 18.7 \mathrm{~kg}$; height: $168.8 \pm 41.4 \mathrm{~cm}$ ) from the same team competing in the First Portuguese League (Europe) voluntarily participated in this study. They were daily monitored with a Global Positioning System (GPS) and the following external load variables were extracted per session: (i) total distance; (ii) running distance; (iii) high-speed running distance; (iv) distance at maximal speed; (v) distance at high accelerations; and (vi) players' training load. The acute load and acute:chronic workload ratio were weekly calculated for each of the GPS measures.

Results. Week-by-week variations ranged from $-57 \%$ to $+115 \%$, depending on the playing position and the variable measured. The within-week variability revealed coefficients of variation between $48 \%$ and $55 \%$, depending on the measure. Considering the differences in mean load between playing positions, significant differences between players were found for the majority of the variables, with the only exceptions being maximal speed and high accelerations distances.

Conclusions. Great between-week variations in the acute load as well as the variability of load within weeks were found. It was observed that acute load was position-dependent.

Key words: association football, performance, training load, external load, periodization

\section{Introduction}

Players' monitoring cycles are a part of a well-implemented approach that controls the training stimulus applied, provides an understanding of the impact on players' wellness, and determines the readiness of professional players [1]. The training stimulus can be quantified by using objective and subjective instruments to determine the external and internal loads imposed on players by the training [2]. External load represents the physical and neuromuscular demands issued by the drills on the athlete, while internal load refers to the biological impact of the external load on the players [3]. Usually, in team sports like soccer, external load moni- toring is part of teams' daily activities. In fact, monitoring is involved in the goal to determine training variations and exposure to spikes in load [4].

The dynamic nature of soccer implies intra- and inter-individual variability $[5,6]$ in terms of the physical demands imposed during training sessions, mainly considering that a significant part of training is based on game-related drills (e.g., positioning games, smallsided games, full-sized games) [7-9]. This variability can be explained by contextual factors such as opponent level, score status, or the half or period of the games $[10,11]$. Owing to the variable nature of training sessions, it is important to pay special attention to fluctuations at the load imposed on players, not only

Correspondence address: Filipe Manuel Clemente, Escola Superior Desporto e Lazer, Instituto Politécnico de Viana do Castelo, Rua Escola Industrial e Comercial de Nun'Álvares, 4900-347, Viana do Castelo, Portugal,

e-mail: Filipe.clemente5@gmail.com

Received: March 15, 2020

Accepted for publication: May 17, 2020

Citation: Hasan UCh, Silva R, Clemente FM. Weekly variations of biomechanical load variables in professional soccer players: comparisons between playing positions. Hum Mov. 2021;22(3):19-34; doi: https://doi.org/10.5114/hm.2021.100321. 
U. Hasan, R. Silva, F. Clemente, Weekly variations of biomechanical load variables in soccer

to control spikes in load but also to identify situations of underload [12, 13]. In fact, a well-implemented monitoring process may benefit the individualization of the training, even in soccer [14].

As described before, contextual factors in soccer determine the variability in the external load [15], and for that reason, some determinant external load variables can be highly different from one match to the next. A study that tested within-subject variability during 5 pre-season matches of a professional soccer team revealed that coefficients of variation were around $6 \%$ for total distance covered, $7 \%$ for mean metabolic power, and $26.2 \%$ for peak metabolic power [6]. Also, when testing the individual match-to-match variability of high-speed running $\left(19.8-25.2 \mathrm{~km} \cdot \mathrm{h}^{-1}\right)$ in professional soccer players, a coefficient of variation of $18.1 \%$ (all players) was found, and a coefficient of variation of $37.1 \%$ was detected for sprinting $\left(>25.2 \mathrm{~km} \cdot \mathrm{h}^{-1}\right)$ [5].

In terms of game-related drills, small-sided games (which are often used by coaches during training sessions) are also highly variable in physical demands (both within and between subjects) [16, 17]. When testing a medium-sided game (10 vs. 10 + goalkeeper) in professional soccer players, coefficients of variation of 4-6\% for total distance, 13-19\% for high-intensity running distance $\left(>16 \mathrm{~m} \cdot \mathrm{s}^{-1}\right)$, and $6-20 \%$ for veryhigh-speed distance $\left(>22 \mathrm{~m} \cdot \mathrm{s}^{-1}\right)$ were found. A smaller format (5 vs. 5 ) played by under-19 players was associated with coefficients of variation of $7 \%$ for total distance, $83 \%$ for running distance $\left(14-20 \mathrm{~km} \cdot \mathrm{h}^{-1}\right)$, and $4.9 \%$ for player load [17].

As exemplified above [16, 17], game-related drills (which occupy the most time during a session) may create low-to-high intra- and inter-variability depending on the external load measures analysed. Thus, it is expected that the weekly acute load (sum of training loads of a week) can also vary within and between weeks [18]. In fact, a progressive and variable workload is expected in the training process. However, extreme spikes or abrupt decreases in loads are not recommended, as these can increase injury risk $[19,20]$.

In addition to within-subject variability, training load can be different from player to player, depending on playing positions and the roles associated with those positions [21]. Distances covered at different speed thresholds, player loads, and accelerations/decelerations are significantly different from position to position during matches [22]. This factor can also affect the load experienced during training sessions, mainly during drills and tasks related to games. Such a hypothesis was confirmed in a study conducted among professional players in which differences in training load measures were found between playing positions [23].
Despite the above-mentioned evidence, there is still a lack of observations concerning the within- and between-subject load imposed on professional players for various measures. Moreover, analyses of acute and chronic load variability over training weeks could be interesting and aid our understanding of the dynamics of a professional team. Finally, the examination of possible differences in the external load between players could help to determine the potential needs for position and reference values.

For these reasons, the purpose of this study was fourfold: (i) to analyse the weekly variations in acute load measures during a season; (ii) to analyse the variability of external load measures within weeks; (iii) to analyse the acute:chronic workload ratios (ACWR) of players during the process; and (iv) to analyse differences in external load measures between playing positions.

\section{Material and methods}

\section{Participants}

Twenty professional soccer players (age: $24.9 \pm$ 3.5 years; body mass: $71.6 \pm 18.7 \mathrm{~kg}$; height: $168.8 \pm$ $41.4 \mathrm{~cm}$ ) from the same team competing in the First Portuguese League (Europe) voluntarily participated in this study. The inclusion criteria were the following: (i) participation in $80 \%$ of the overall training sessions of the season; and (ii) not being injured for a period longer than 2 consecutive weeks. The players were classified on the basis of their typical playing positions; there were thus 5 defenders, 8 midfielders, and 7 attackers. All the participants were informed about the study design and protocol.

\section{Experimental approach}

The study followed a descriptive research design. Data collection occurred from the beginning (June) until the end of the 2018/2019 season (May). The players were daily monitored with a $10-\mathrm{Hz}$ Global Positioning System (GPS) unit during the entire training session. The weekly acute and chronic training loads were calculated. The within-week coefficient of variation was also determined. Finally, comparisons of external loads between playing positions were also tested.

\section{External load measures}

Each player was daily monitored with a portable GPS unit $(10 \mathrm{~Hz}$, including EGNOS correction, JOHAN Sports, Noordwijk, The Netherlands) consisting of a GPS 
sensor, an accelerometer, a gyroscope, and a magnetometer $(100 \mathrm{~Hz}, 3$ axes, $\pm 16 \mathrm{~g})$. The GPS and model were validated and tested for reliability [24]. The GPS unit was placed in a vest, with a specific bag located in the player's dorsal region. The following GPS-derived biomechanic variables were daily collected during the entire training session: (i) total distance (unit: meters); (ii) running distance (at $14.0-19.9 \mathrm{~km} \cdot \mathrm{h}^{-1}$ ) (unit: meters); (iii) high-speed running distance (at $\geq 20.0 \mathrm{~km} \cdot \mathrm{h}^{-1}$ ) (unit: meters); (iv) distance at maximum speed (unit: meters); (v) distance at high accelerations (unit: meters); and (vi) player's training load (unit: g), which represents the total acceleration difference between 2 consecutive time steps (time step 0, time step 1); the length of the 3 -dimensional vector of accelerations in the anteroposterior, mediolateral, and craniocaudal axes was also daily collected.

The weekly acute training load was calculated by adding the values of all training sessions of the week for each external load measure. The weekly chronic training load was calculated by representing the rolling average of a given external load variable in the previous 4 weeks. Then, the ACWR was calculated. The interpretation of the ratio was used as follows [25]: $<1=$ athlete in a well-prepared state; $0.8-1.3=$ training 'sweet spot,' where injury risk is reduced; $>1.3=$ over-reaching; $>1.5$ = danger zone, more at risk of injury; $>1.8=$ danger zone; 2 = further increased risk of injury.

\section{Statistical procedures}

The statistical processing was done by using the Statistical Package for the Social Sciences (SPSS for Windows, version 22.0, IBM Corp., Armonk, USA). The results were presented in the form of text, tables, and figures. Means, standard deviations, the skewness coefficient, and coefficient of variation were calculated. The variety of training variables was reported as percentages in comparison with the previous week. Oneway analysis of variance (ANOVA) and the Scheffé post-hoc test differences were applied. Inter-playing position practical differences were assessed by calculating the Cohen's $d$ effect size (ES) [26]. The interpretation of inference magnitudes was used as follows [27]: $<0.2=$ slight; $0.2-0.6=$ small; $0.6-1.2=$ moderate; $1.2-2.0=$ large; $2.0-4.0$ very large; and $>4.0$ extremely large. Statistical significance of the results was accepted at $p<0.05$.

\section{Ethical approval}

The research related to human use has complied with all the relevant national regulations and institu- tional policies, has followed the tenets of the Declaration of Helsinki, and has been approved by the local ethical committee.

\section{Informed consent}

Informed consent has been obtained from all individuals included in this study.

\section{Results}

The highest weekly change in total distance reached $81 \%$ (from week 16 to week 17) for the defenders. Meanwhile, the midfielders obtained $80 \%$ (from week 18 to week 19) and the attackers reached 115\% (from week 7 to week 8). The lowest change equalled $-56 \%$ (from week 19 to week 20), $-50 \%$ (from week 17 to week 18), and $-47 \%$ (from week 19 to week 20) for the playing positions of defenders, midfielders, and attackers, respectively (Figure 1).

The within-week coefficient of variation was highest in week 20 (35\%), week 21 (48\%), and week 4 (50\%) for the playing positions of defenders, midfielders, and attackers, respectively. It was the lowest in week 16 (4\%) for the defenders, and for the positions of midfielders and attackers it reached $9 \%$ and $8 \%$ in week 3 , respectively.

The mean weekly acute and chronic total distance reached 26,630, 25,439 for the defenders, 24,351, 23,337 for the midfielders, and 25,341, 24,387 for the attackers. ACWR equalled 1.05 for the defenders, and for the positions of midfielders and attackers it reached 1.04 .

The highest weekly change in running distance reached $88 \%$ and $95 \%$ (from week 7 to week 8 ) for the defenders and attackers positions, respectively. Meanwhile, the midfielders obtained 92\% (from week 18 to week 19 ). The lowest change equalled $-57 \%,-57 \%$, and $-49 \%$ (from week 19 to week 20) for the playing positions of defenders, midfielders, and attackers, respectively (Figure 2).

The within-week coefficient of variation was highest in week 20 (50\%), week 18 (52\%) and week 10 (53\%) for the playing positions of defenders, midfielders, and attackers, respectively. It was the lowest in week $9(4 \%)$ for the defenders, and for the positions of midfielders and attackers it reached $17 \%$ and $14 \%$ in week 3 , respectively.

The mean weekly acute and chronic running distance reached 2170.7, 2164.9 for the defenders, 2314.4, 2279.1 for the midfielders, and 2529.4, 2496.2 for the attackers. ACWR equalled 1 for the defenders, and for the positions of midfielders and attackers it reached 1.01. 
a

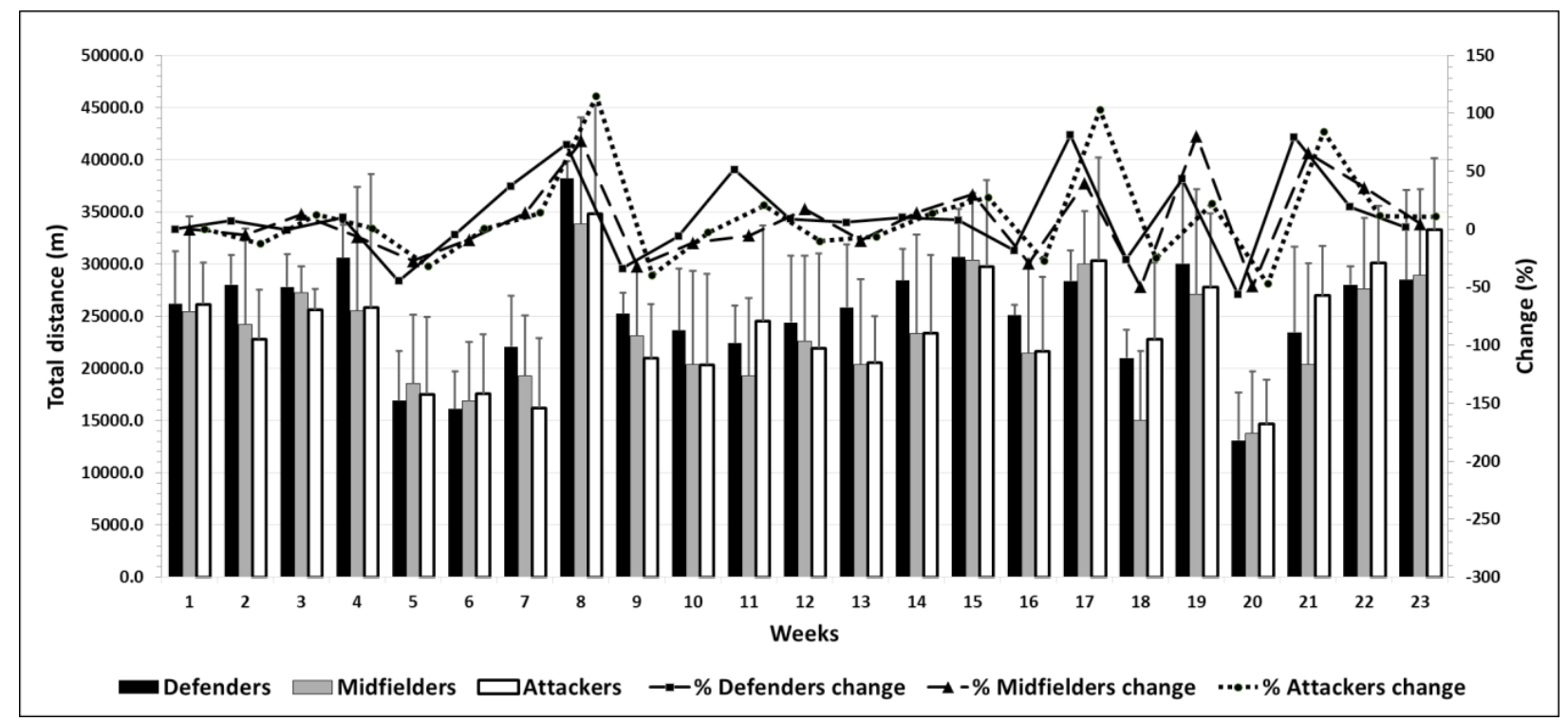

b

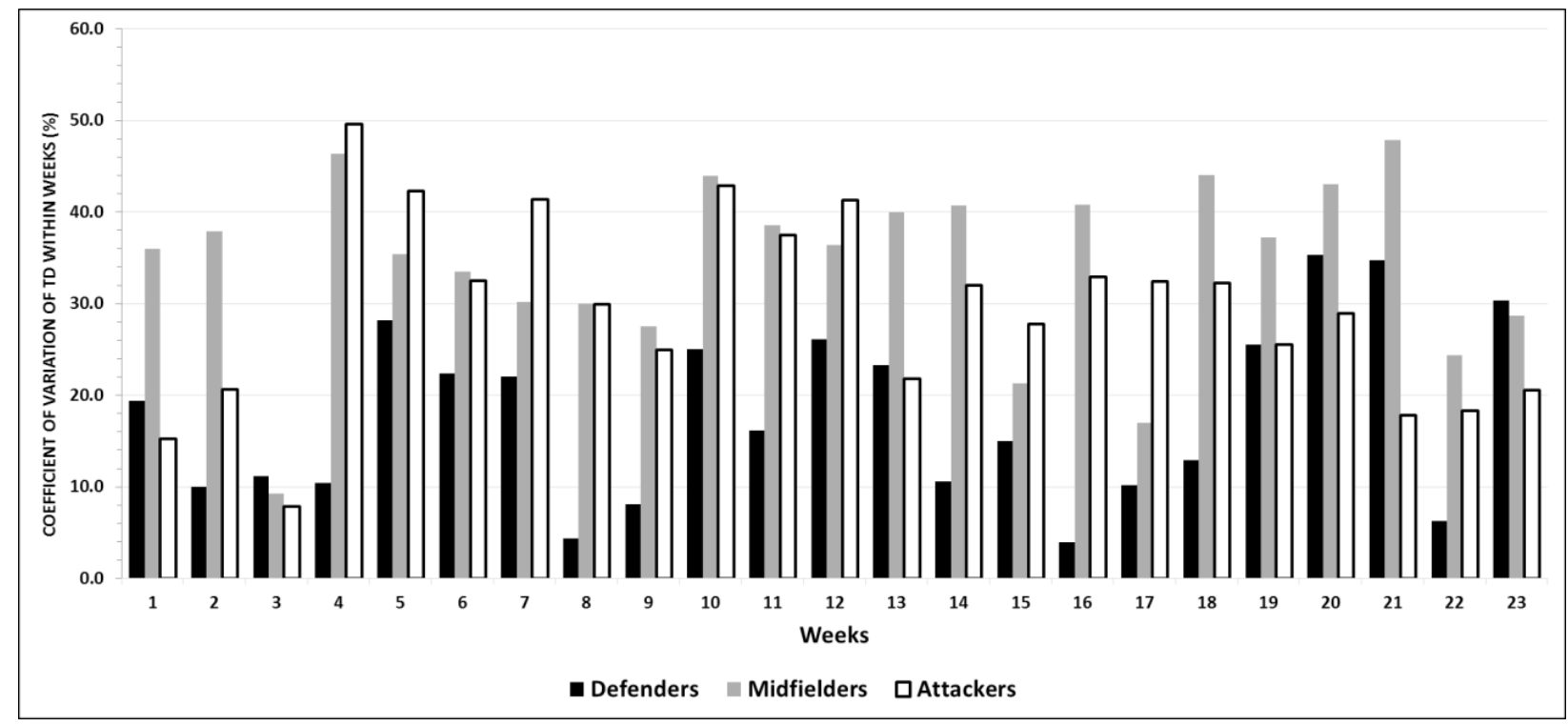

C

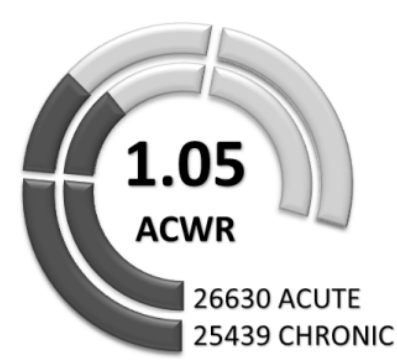

Defenders

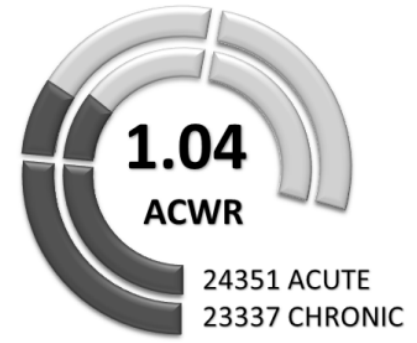

Midfielders

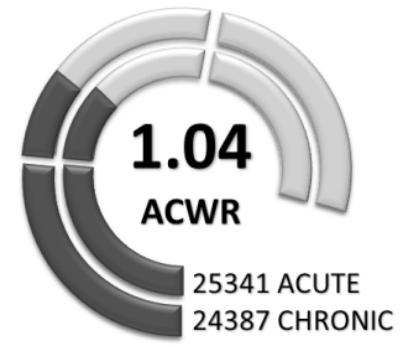

Attackers

TD - total distance, ACWR - acute:chronic workload ratio

Figure 1. (a) Mean (SD) and weekly changes (\%) in total distance over 23 weeks; (b) within-week total distance variations; and (c) mean weekly acute and chronic total distance and ACWR for playing positions 
a

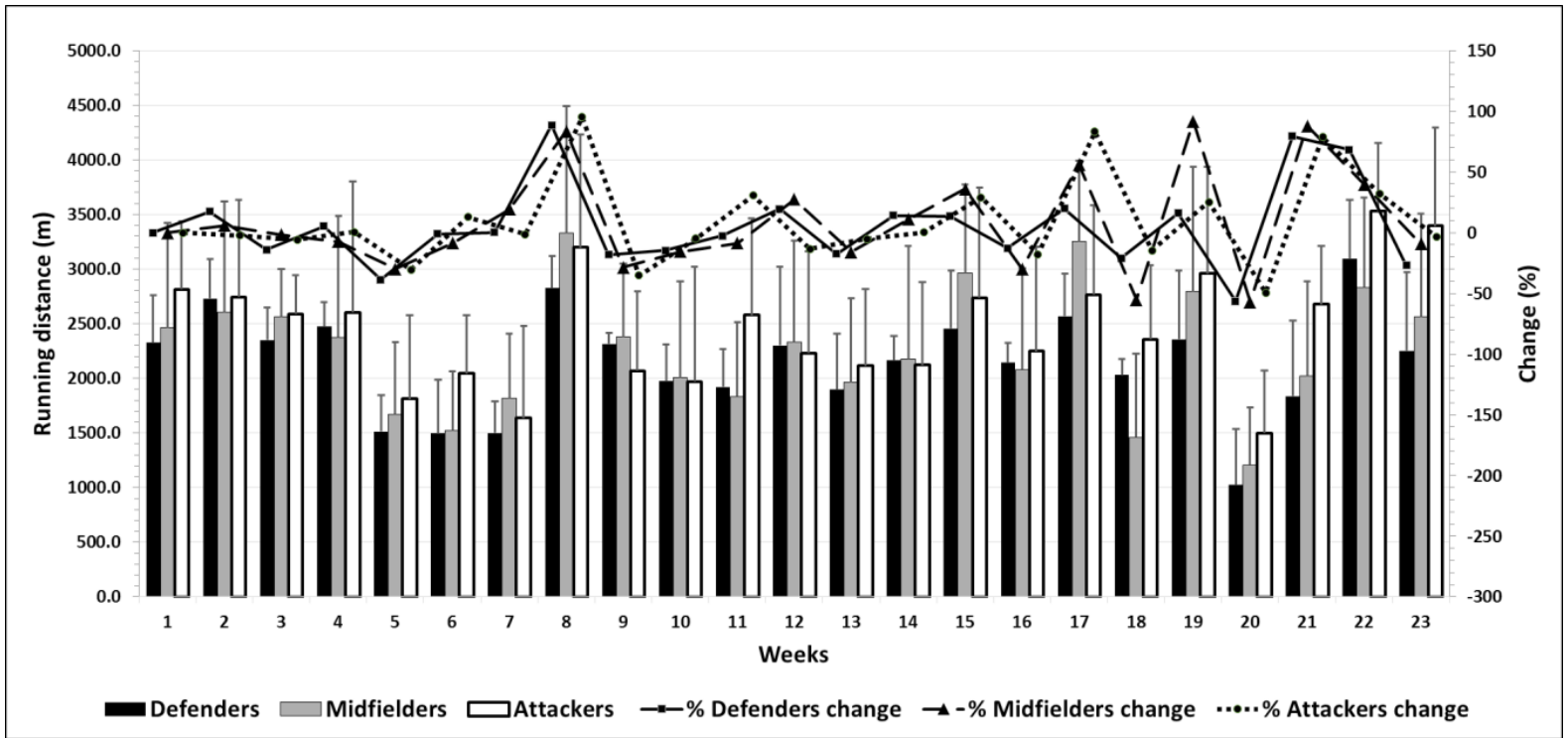

b

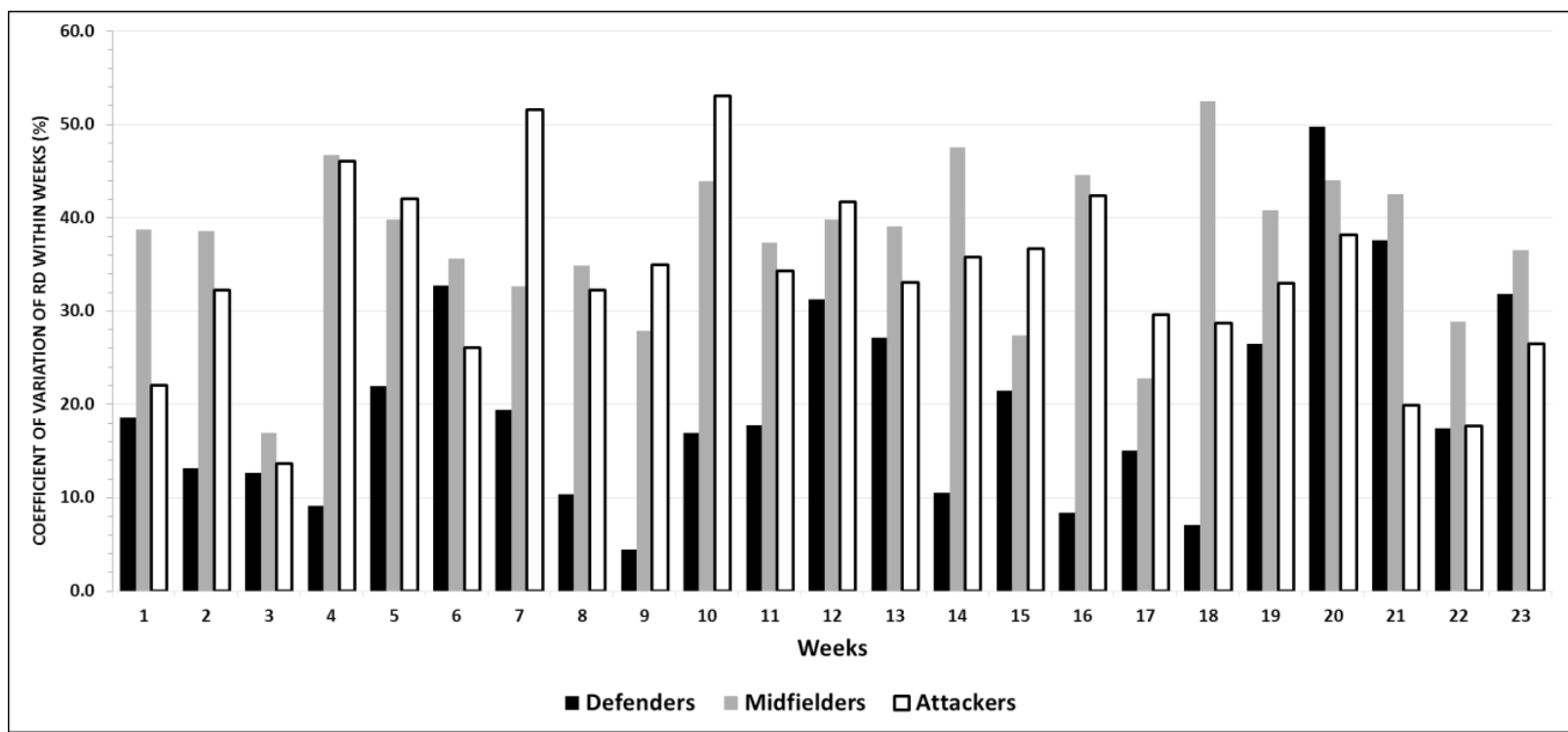

C

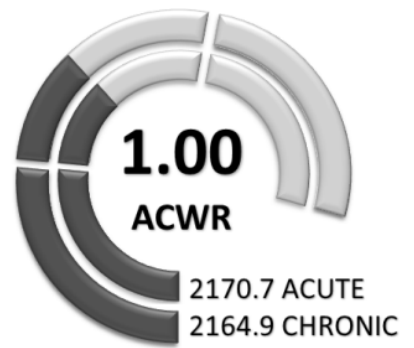

Defenders

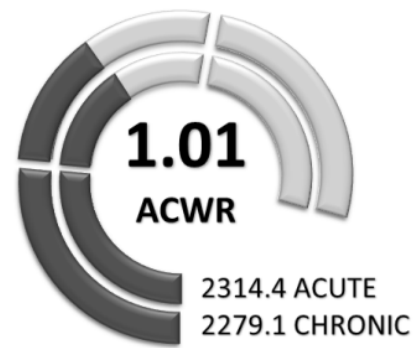

Midfielders

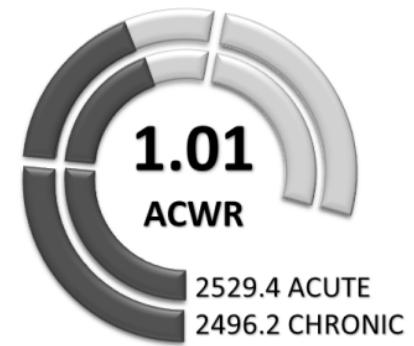

Attackers

RD - running distance, ACWR - acute:chronic workload ratio

Figure 2. (a) Mean (SD) and weekly changes (\%) in running distance over 23 weeks; (b) within-week running distance variations; and (c) mean weekly acute and chronic running distance and ACWR for playing positions 


\section{HUMAN MOVEMENT}

U. Hasan, R. Silva, F. Clemente, Weekly variations of biomechanical load variables in soccer

a

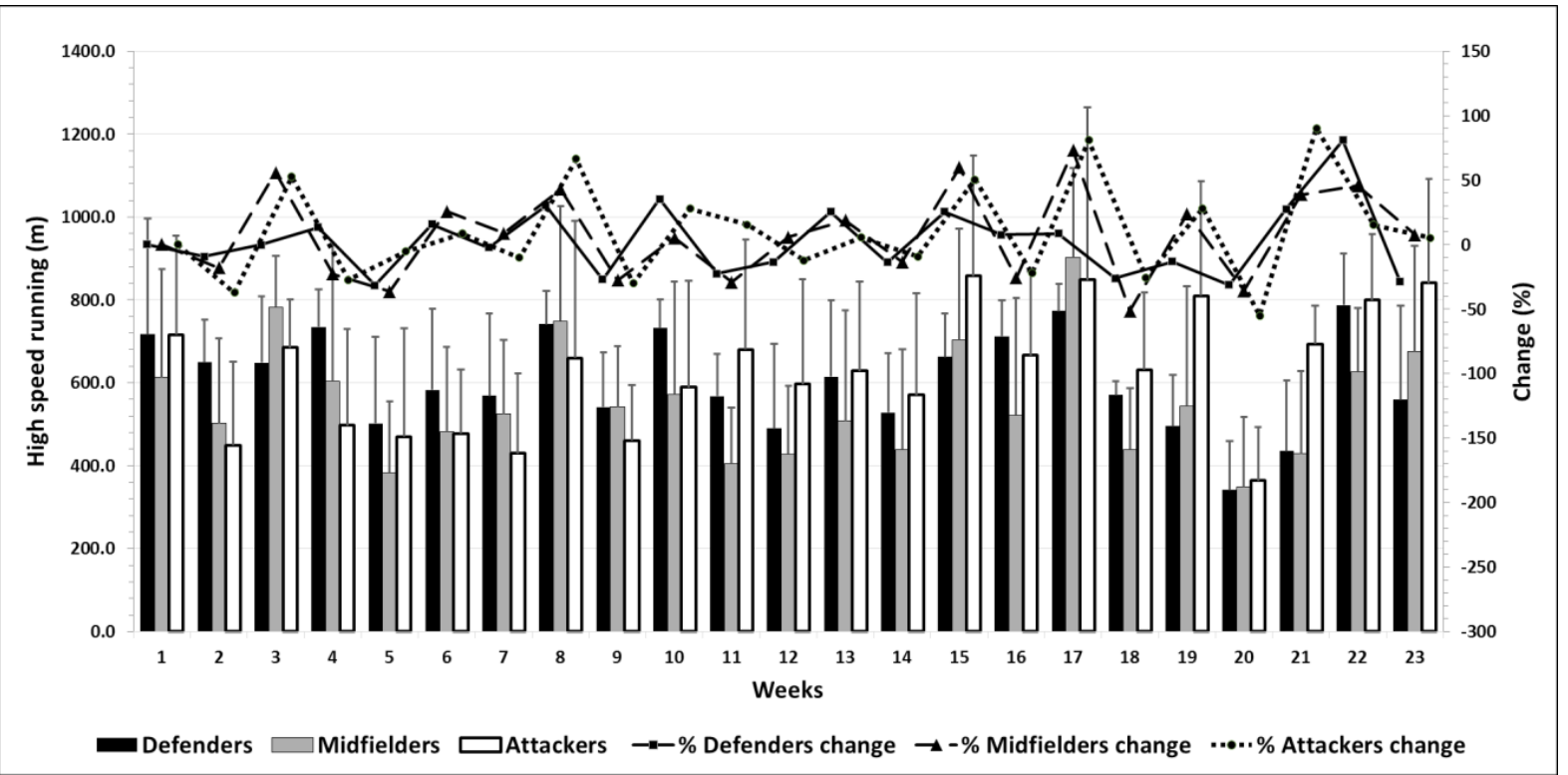

b

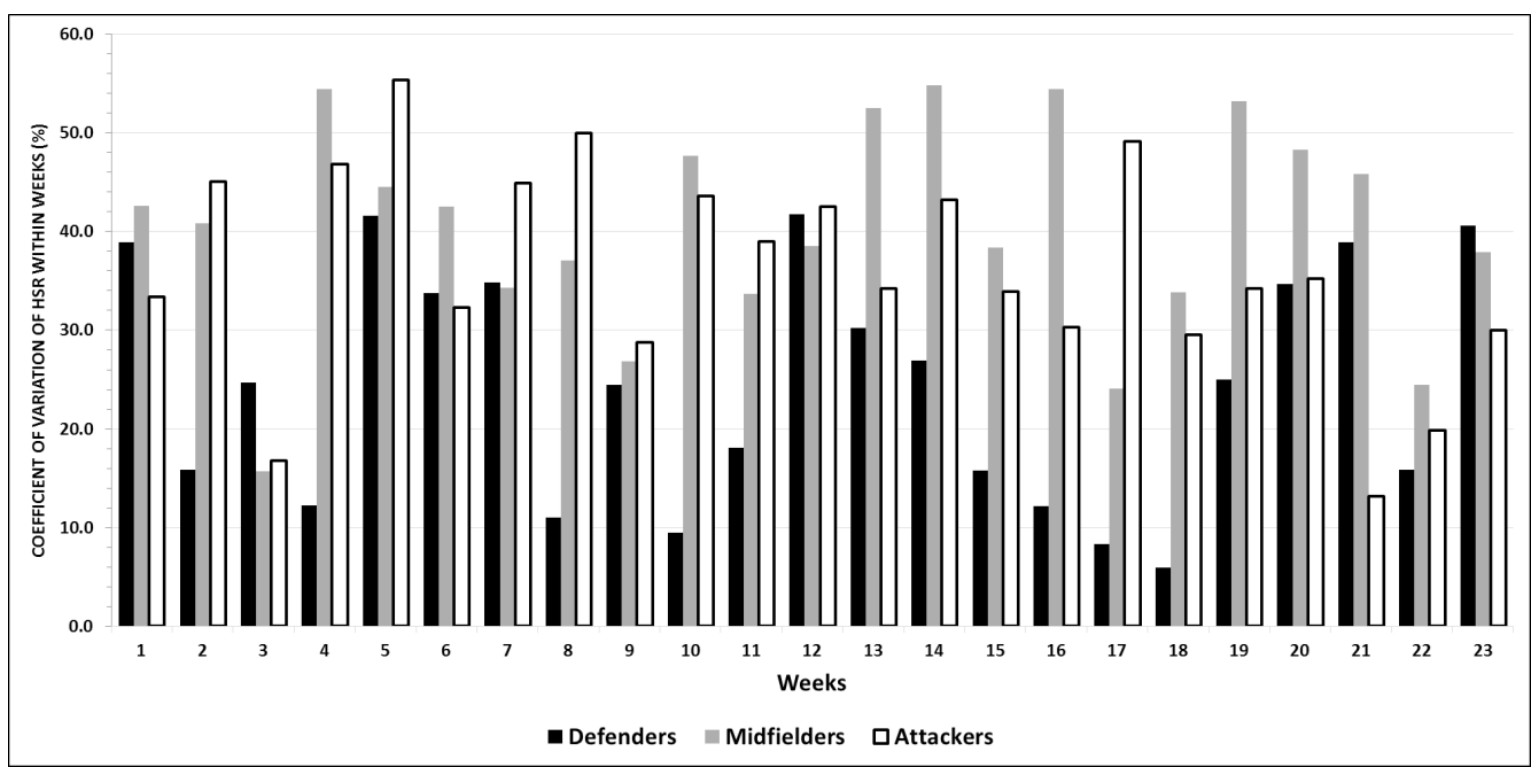

C

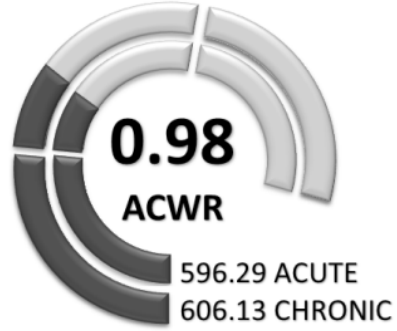

Defenders

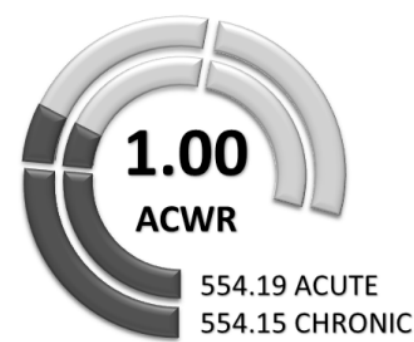

Midfielders

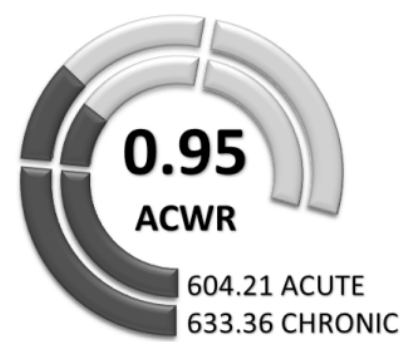

Attackers

HSR - high-speed running distance, ACWR - acute:chronic workload ratio

Figure 3. (a) Mean (SD) and weekly changes (\%) in high-speed running distance over 23 weeks; (b) within-week high-speed running distance variations; and (c) mean weekly acute and chronic high-speed running distance and ACWR for playing positions 
a

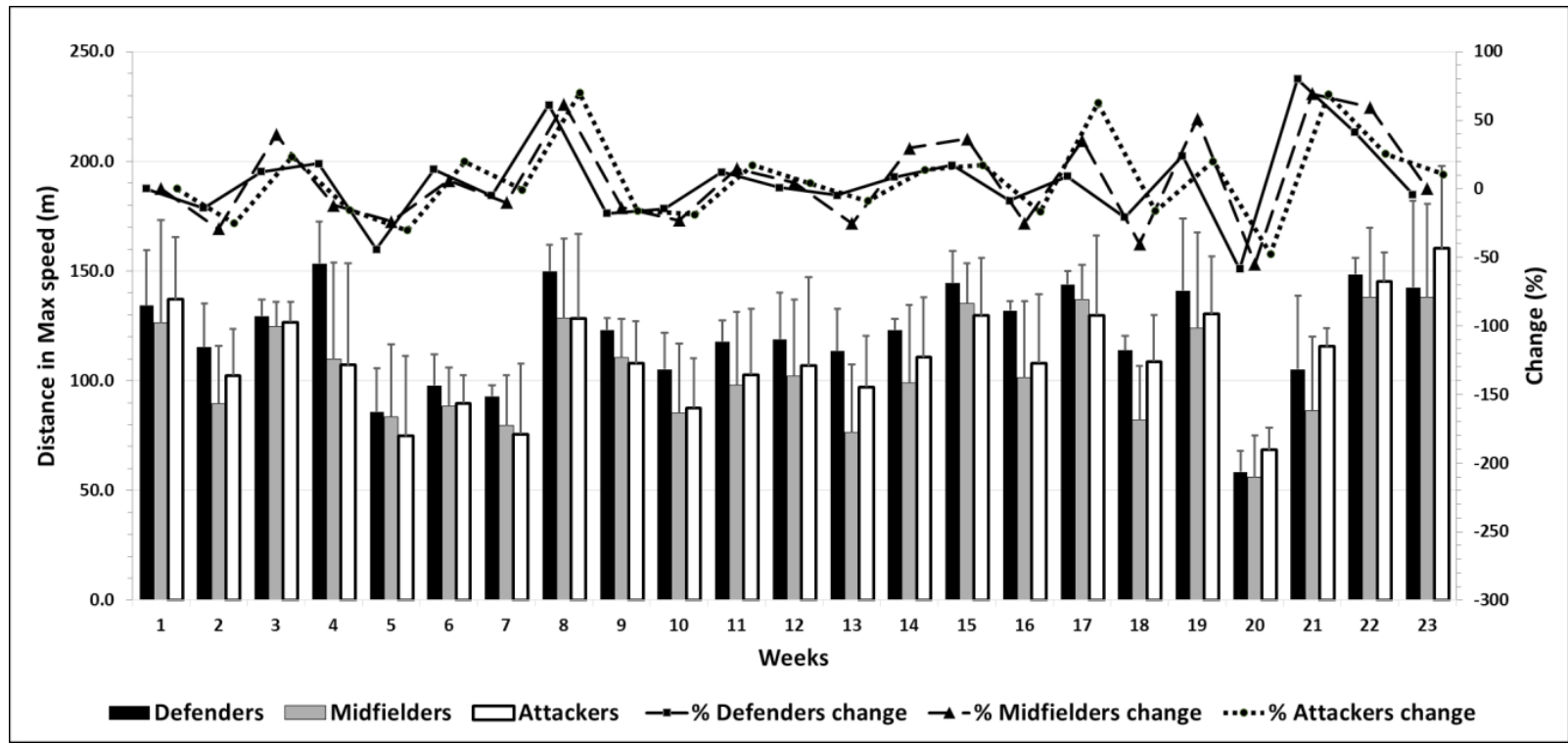

b

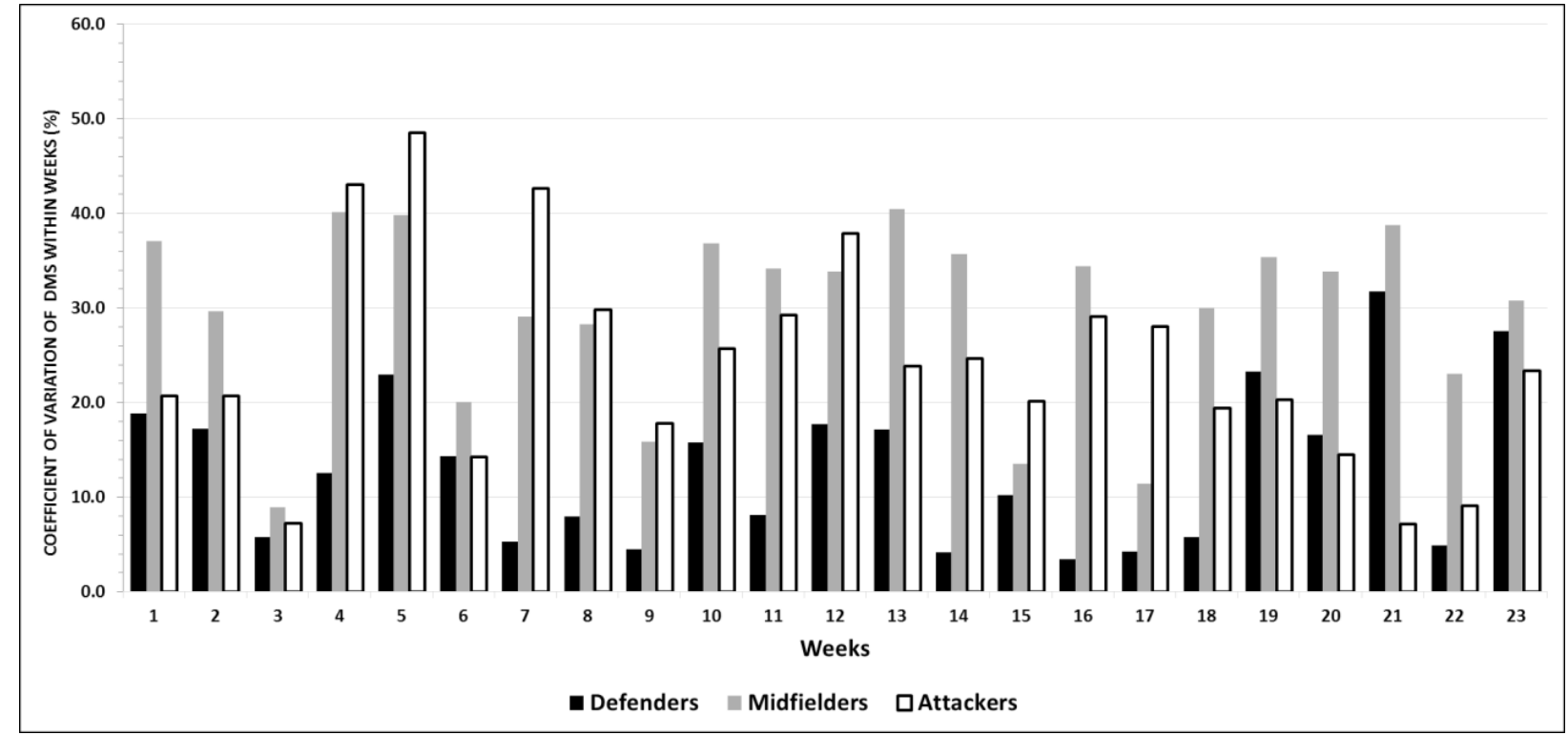

C

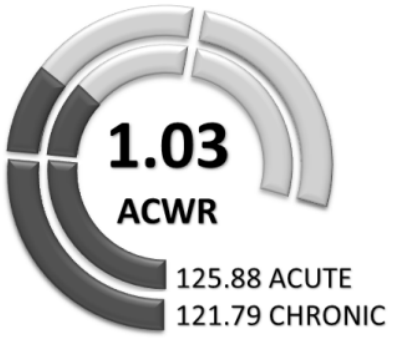

Defenders

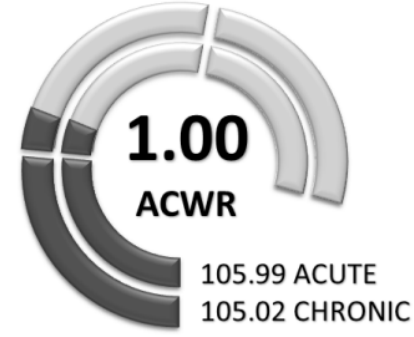

Midfielders

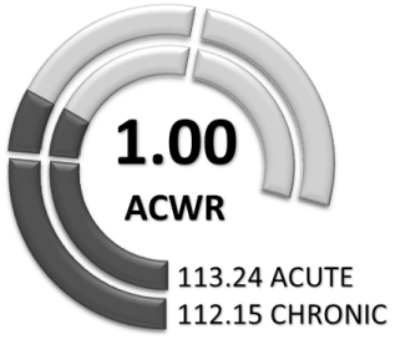

Attackers

DMS - distance at maximum speed, ACWR - acute:chronic workload ratio

Figure 4. (a) Mean (SD) and weekly changes (\%) in maximum speed distance over 23 weeks; (b) within-week maximum speed distance variations; and (c) mean weekly acute and chronic maximum speed distance and ACWR for playing positions 


\section{HUMAN MOVEMENT}

U. Hasan, R. Silva, F. Clemente, Weekly variations of biomechanical load variables in soccer

a

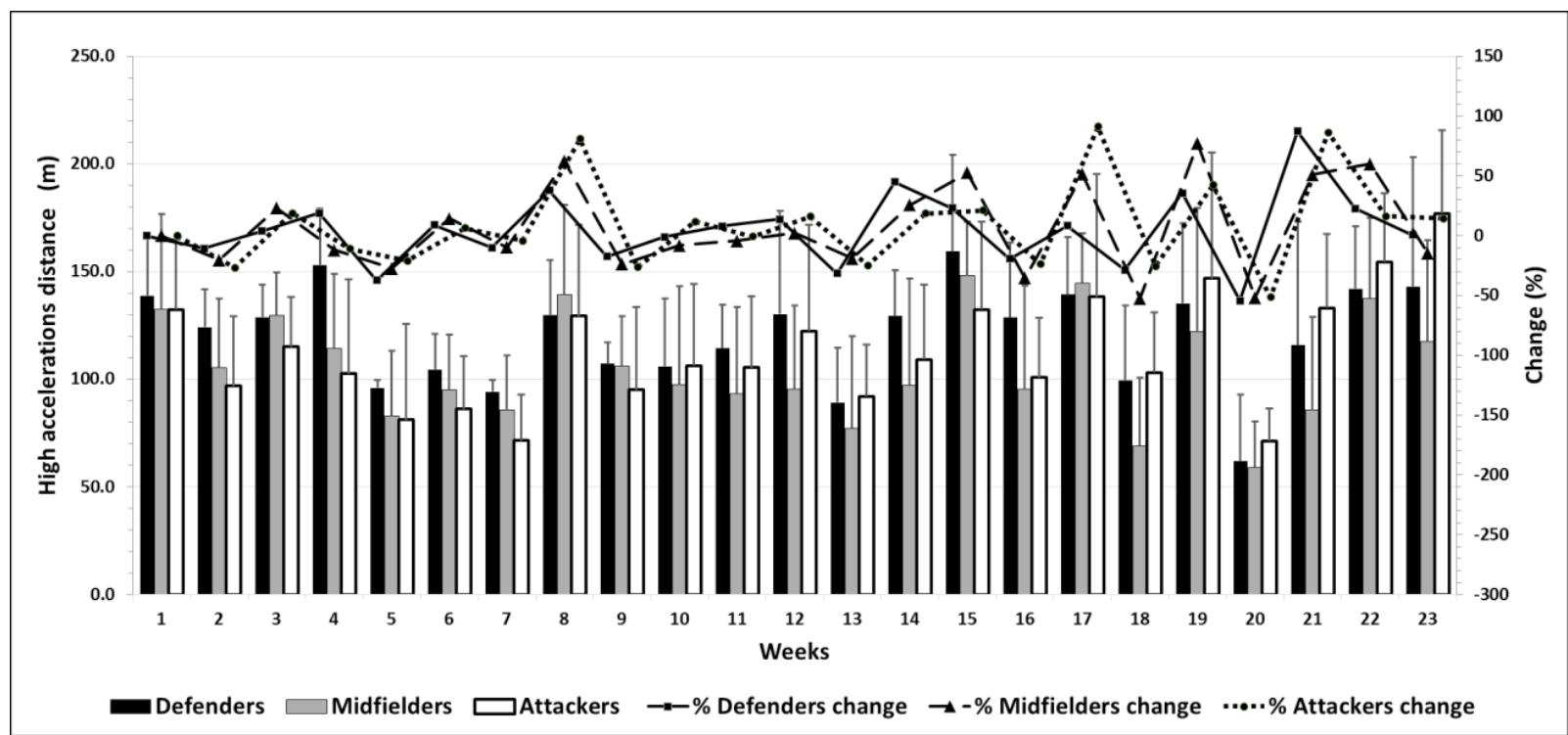

b

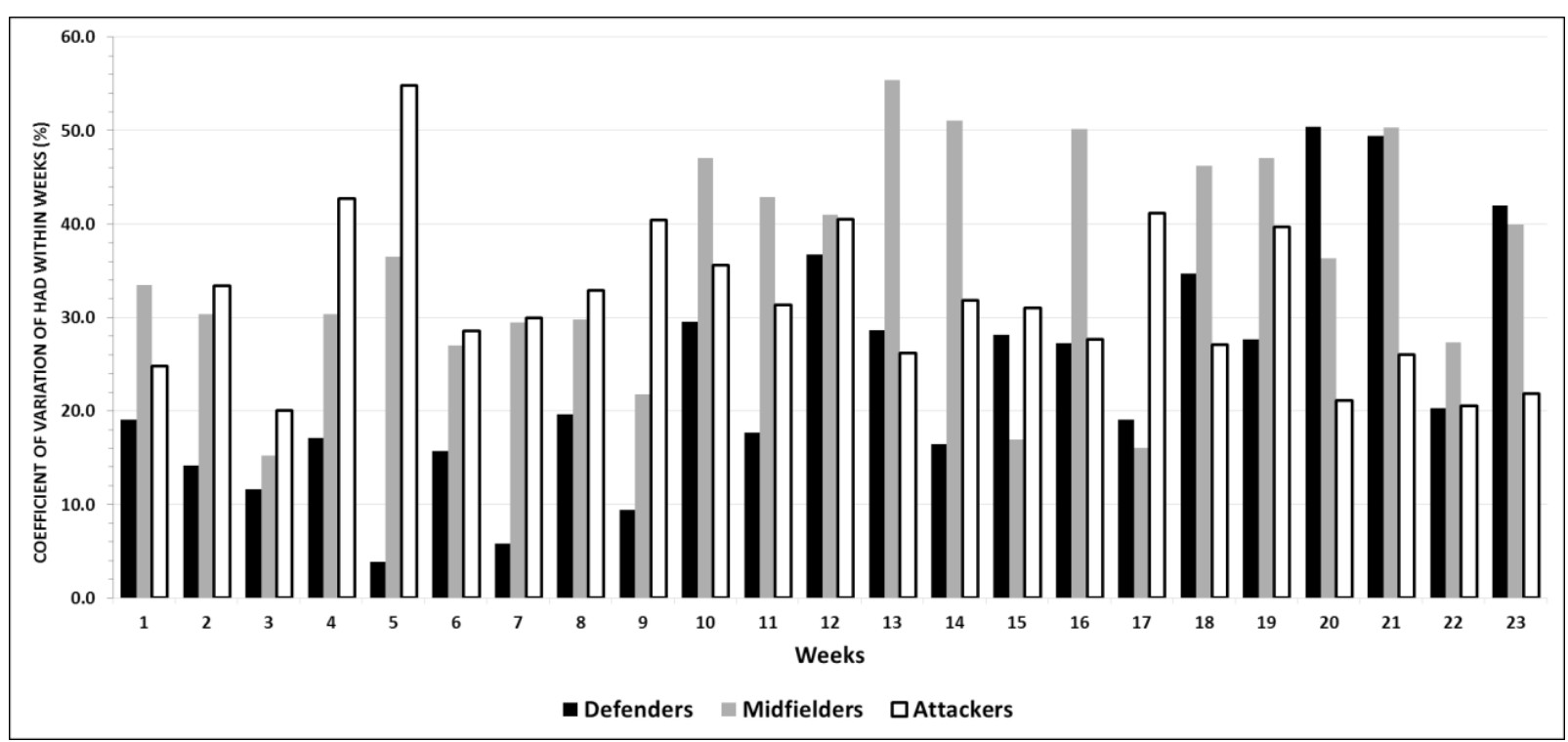

C

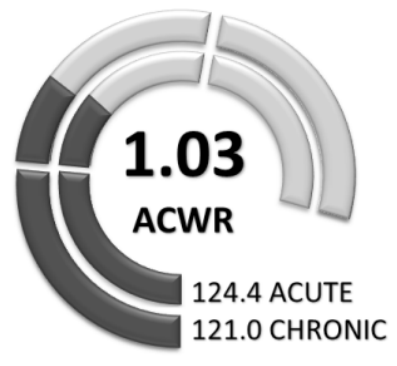

Defenders

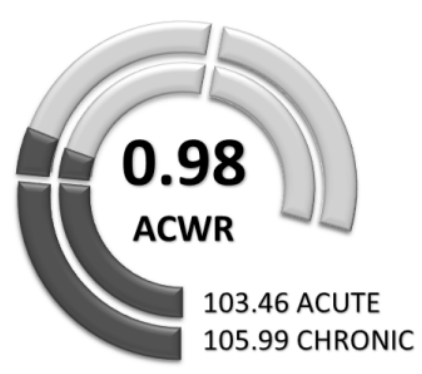

Midfielders

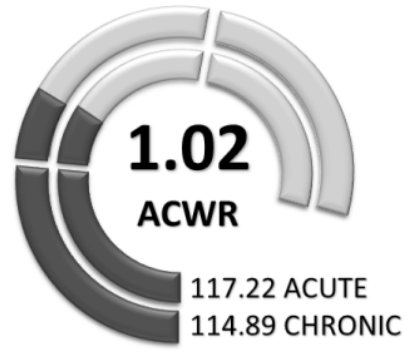

Attackers

HAD - high accelerations distance, ACWR - acute:chronic workload ratio

Figure 5. (a) Mean (SD) and weekly changes (\%) in high accelerations distance over 23 weeks; (b) within-week high accelerations distance variations; and (c) mean weekly acute and chronic high accelerations distance and ACWR for playing positions 


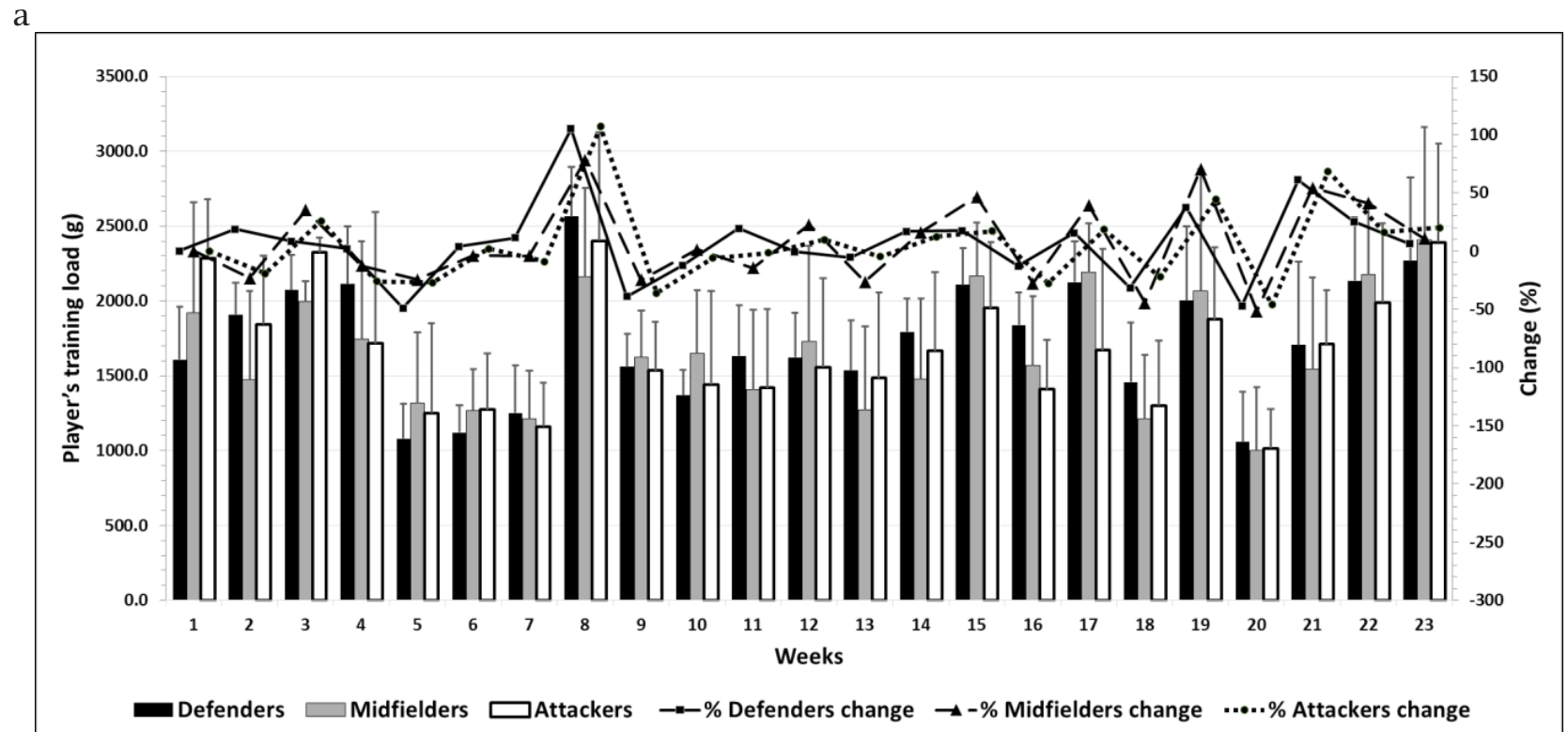

b

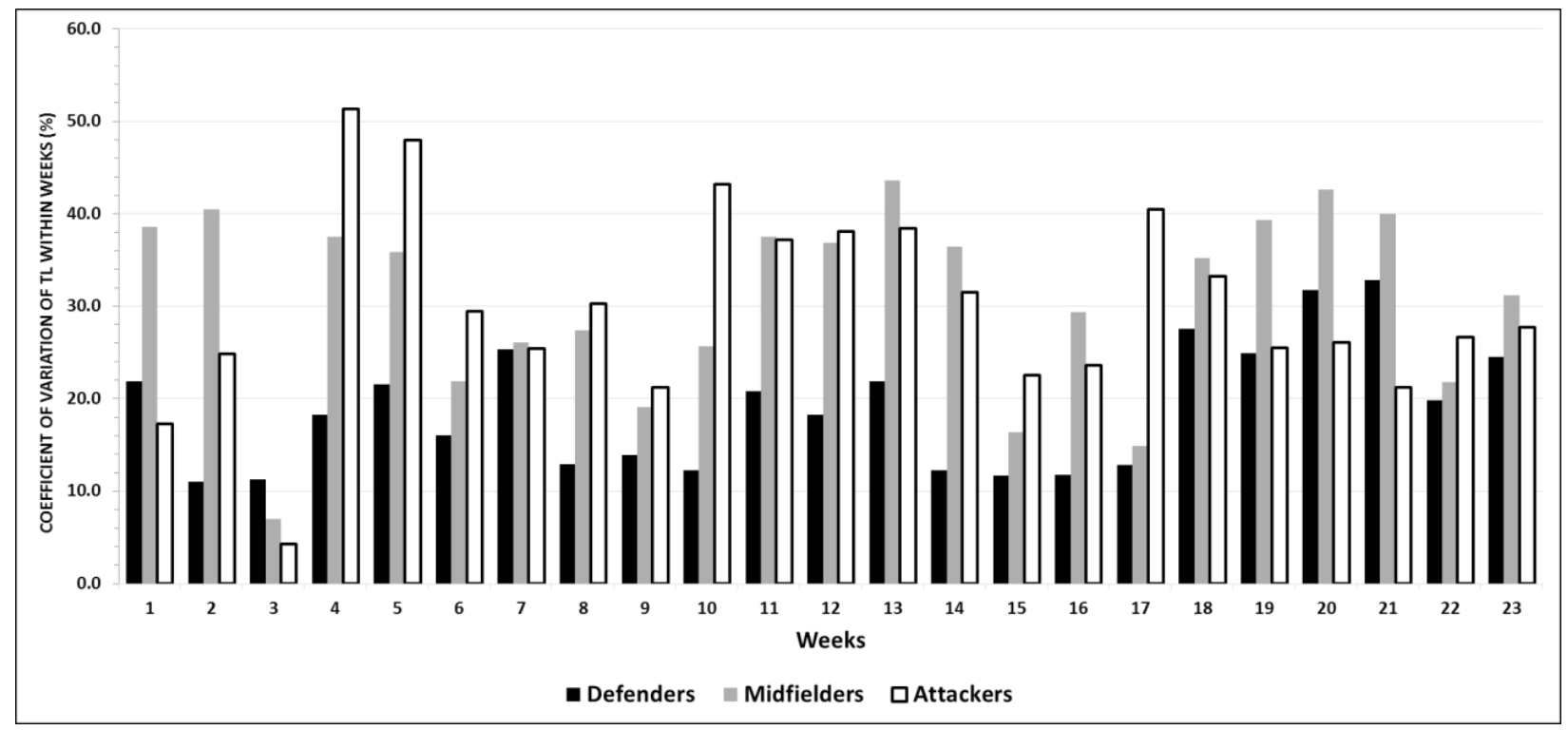

C

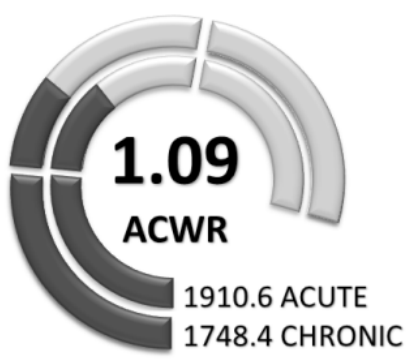

Defenders

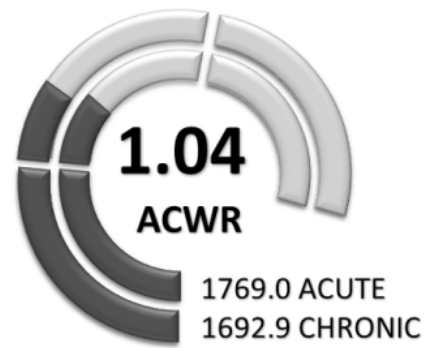

Midfielders

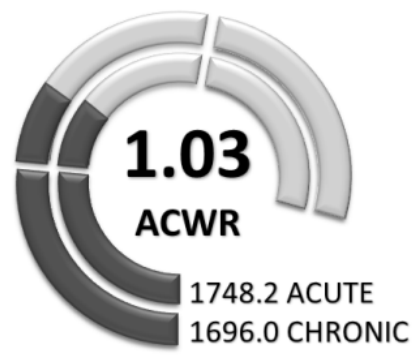

Attackers

TL - training load, ACWR - acute:chronic workload ratio

Figure 6. (a) Mean (SD) and weekly changes (\%) in weekly training load over 23 weeks; (b) within-week load variations; and (c) mean weekly acute and chronic training load and ACWR for playing positions 
U. Hasan, R. Silva, F. Clemente, Weekly variations of biomechanical load variables in soccer

The highest weekly change in high-speed running distance reached 81\% (from week 21 to week 22), 73\% (from week 16 to week 17), and 90\% (from week 20 to week 21) for the playing positions of defenders, midfielders, and attackers, respectively. The lowest change equalled $-32 \%$ (from week 4 to week 5), $-51 \%$ (from week 17 to week 18), and -55\% (from week 19 to week 20) for the defenders, midfielders, and attackers, respectively (Figure 3 ).

The within-week coefficient of variation was highest in week 12 (42\%), week 14 (55\%), and week 5 (55\%) for the playing positions of defenders, midfielders, and attackers, respectively. It was the lowest in week 18 (6\%), week $3(16 \%)$, and week 21 (13\%) for the defenders, midfielders, and attackers, respectively.

The mean weekly acute and chronic high-speed running distance reached 596.29, 606.13 for the defenders, 554.19, 554.15 for the midfielders, and 604.21, 633.36 for the attackers. ACWR equalled 0.98, 1, and 0.95 for the playing positions of defenders, midfielders, and attackers, respectively.

The highest weekly change in maximum speed distance reached $80 \%$ and $69 \%$ (from week 20 to week 21) for the defenders and midfielders, respectively. Meanwhile, the attackers obtained 70\% (from week 7 to week 8). The lowest change equalled $-59 \%,-55 \%$, and $-47 \%$ (from week 19 to week 20) for the playing positions of defenders, midfielders, and attackers, respectively (Figure 4).

The within-week coefficient of variation was highest in week 21 (32\%), week 13 (40\%), and week 5 (48\%) for the playing positions of defenders, midfielders, and attackers, respectively. It was the lowest in week 16 (3\%), week $3(9 \%)$, and week 21 (7\%) for the defenders, midfielders, and attackers, respectively.

The mean weekly acute and chronic maximum speed distance reached 125.88, 121.79 for the defenders, 105.99, 105.02 for the midfielders, and 113.24, 112.15 for the attackers. ACWR equalled 1.03, 1, and 1 for the playing positions of defenders, midfielders, and attackers, respectively.

The highest weekly change in high accelerations distance reached 87\% (from week 20 to week 21), 77\% (from week 18 to week 19), and 91\% (from week 16 to week 17) for the playing positions of defenders, midfielders, and attackers, respectively. The lowest change equalled $-54 \%$ and $-51 \%$ (from week 19 to week 20) for the positions of defenders and attackers, respectively, and $-52 \%$ (from week 17 to week 18) for the midfielders (Figure 5).

The within-week coefficient of variation was highest in week 20 (50\%), week $13(55 \%)$, and week 5 (55\%) for the playing positions of defenders, midfielders, and attackers, respectively. It was the lowest in week 5 (4\%) for the defenders, and in week 3 (15\% and 20\%) for the midfielders and attackers, respectively.

The mean weekly acute and chronic high accelerations distance reached 124.4, 121.0 for the defenders, 103.46, 105.99 for the midfielders, and 117.22, 114.89 for the attackers. ACWR equalled 1.03, 0.98, and 1.02 for the playing positions of defenders, midfielders, and attackers, respectively.

The highest weekly change in training load reached $105 \%, 78 \%$, and $107 \%$ (from week 7 to week 8) for the defenders, midfielders, and attackers, respectively. Meanwhile, the lowest of change equalled $-49 \%$ for the defenders and $-52 \%$ and $-46 \%$ (from week 19 to week 20) for the playing positions of midfielders and attackers, respectively (Figure 6).

The within-week coefficient of variation was highest in week 21 (33\%), week 13 (44\%), and week 4 (51\%) for the playing positions of defenders, midfielders, and attackers, respectively. It was the lowest in week $2(11 \%)$ for the defenders and in week 3 ( $7 \%$ and $4 \%)$ for the midfielders and attackers, respectively.

The mean weekly acute and chronic training load reached 1910.6, 1748.4 for the defenders, 1769.0, 1692.9 for the midfielders, and 1748.2, 1696.0 for the attackers. ACWR equalled 1.09, 1.04, and 1.03 for the playing positions of defenders, midfielders, and attackers, respectively.

The values of the mean, standard deviation, and skewness of biomechanical load variables were found to be dependent on the playing positions. The skewness values ranged between -0.712 and 0.888 (Table 1 ).

The descriptive parameters for biomechanical load variables for each playing position are presented in Table 2. Significant ANOVA differences were found among playing positions $(p<0.05)$ in all variables except maximum speed and high accelerations distance, with moderate $E S$ for differences in running distance $(d=0.610)$ between the defenders and attackers. Small ES was observed for differences in: (i) total distance $(d=0.221)$ between the defenders and midfielders; (ii) running distance $(d=0.506)$ between the defenders and midfielders; (iii) sprinting distance $(d=0.241)$ between the defenders and attackers. The slightest $E S$ was noted for differences in: (i) total distance $(d=0.198)$ between the defenders and attackers; (ii) sprinting distance $(d=0.134)$ between the midfielders and attackers.

Superscripted letters indicate significant post-hoc differences when compared with specific playing position. 
Table 1. Biomechanical load variables (mean \pm standard deviation and skewness) for playing positions

\begin{tabular}{lccc}
\hline Biomechanics variables & Playing positions & Mean $\pm S D$ & Skewness \\
\hline & Defenders & $5250.85 \pm 1456.76$ & 0.11 \\
Total distance $(\mathrm{m})$ & Midfielders & $5586.74 \pm 1574.06$ & 0.61 \\
& Attackers & $5539.44 \pm 1455.39$ & 0.89 \\
\hline & Defenders & $445.73 \pm 161.85$ & 0.23 \\
Running distance $(\mathrm{m})$ & Midfielders & $545.92 \pm 22.50$ & 0.45 \\
& Attackers & $565.27 \pm 220.75$ & 0.53 \\
\hline & Defenders & $125.48 \pm 67.81$ & 0.35 \\
High-speed running distance $(\mathrm{m})$ & Midfielders & $132.97 \pm 74.50$ & 0.44 \\
& Attackers & $143.11 \pm 77.14$ & 0.55 \\
\hline & Defenders & $25.10 \pm 4.14$ & -0.62 \\
Distance at maximum speed $(\mathrm{m})$ & Midfielders & $25.07 \pm 3.53$ & -0.63 \\
& Attackers & $25.35 \pm 4.04$ & -0.71 \\
\hline & Defenders & $24.92 \pm 10.30$ & 0.17 \\
Distance at high accelerations $(\mathrm{m})$ & Midfielders & $25.46 \pm 7.99$ & 0.45 \\
& Attackers & $25.92 \pm 9.45$ & 0.21 \\
\hline
\end{tabular}

Table 2. Differences among playing positions for biomechanical load variables determined by analysis of variance (ANOVA), with Scheffé post-hoc test differences and effect size for pair comparisons

\begin{tabular}{|c|c|c|c|c|}
\hline \multirow{2}{*}{ Biomechanics variables } & \multirow{2}{*}{$\begin{array}{c}\text { ANOVA } \\
\mathrm{F}(\mathrm{p})\end{array}$} & \multicolumn{3}{|c|}{ Post hoc (effect size) } \\
\hline & & $\mathrm{D}$ & M & A \\
\hline Total distance $(\mathrm{m})$ & $8.74(<0.001)$ & ${ }^{\mathrm{M}}(0.221),{ }^{\mathrm{A}}(0.198)$ & $\mathrm{D},-\mathrm{A}(0.031)$ & $\mathrm{D},-\mathrm{M}$ \\
\hline Running distance (m) & $57.26(<0.001)$ & ${ }^{\mathrm{M}}(0.506),{ }^{\mathrm{A}}(0.610)$ & $\mathrm{D},-\mathrm{A}(0.087)$ & $\mathrm{D},-\mathrm{M}$ \\
\hline High-speed running distance (m) & $8.84(<0.001)$ & $-\mathrm{M}(0.105),{ }^{\mathrm{A}}(0.241)$ & $-\mathrm{D},{ }^{\mathrm{A}}(0.134)$ & D, M \\
\hline Distance at maximum speed (m) & $1.08(0.34)$ & $-\mathrm{M}(0.009),-\mathrm{A}(0.063)$ & $-\mathrm{D},-\mathrm{A}(0.076)$ & $-\mathrm{D},-\mathrm{M}$ \\
\hline Distance at high accelerations (m) & $1.79(0.168)$ & -M (0.060), -A (0.102) & $-\mathrm{D},-\mathrm{A}(0.053)$ & $-\mathrm{D},-\mathrm{M}$ \\
\hline
\end{tabular}

D - defenders, M - midfielders, A - attackers, - stands for no significant differences

\section{Discussion}

The present study had four main purposes: (i) to analyse the weekly variations in acute load measures during a season; (ii) to analyse the variability of external load measures within weeks; (iii) to analyse ACWRs of players during the process; and (iv) to analyse differences in external load measures between playing positions. The external load measures of total distance, running distance, high-speed running distance, distance at maximum speed, distance at high accelerations, and players' training load were monitored daily over a full season. Weekly variations and ACWRs were calculated for each training session.

Considering the first objective, it was found that the highest week-by-week variation in total distance was $-56 \%$ (decrease in loading) and $115 \%$ (increase in loading). Running distance varied from a peak drop of $-57 \%$ to a peak increase of $92 \%$. High-speed run- ning distance had a maximum weekly decrease of $-55 \%$ and a maximum increase of $90 \%$. Maximal speed distance varied from a peak decrease of $-59 \%$ to a peak increase of $80 \%$. High accelerations distance varied from a maximum decrease of $-54 \%$ to a maximum increase of $91 \%$. Finally, the players' training load varied from a peak decrease of $-52 \%$ to a peak increase of $105 \%$.

Considering the within-week variability of load (second objective), we recorded peaks of the coefficient of variation of $50 \%$ for total distance, $52 \%$ for running distance, $55 \%$ for high-speed running distance, $48 \%$ for maximal speed distance, $55 \%$ for high accelerations distance, and $51 \%$ for players' training load.

With reference to the third objective, mean ACWRs for different players (i.e., defenders, midfielders, and attackers) varied from 1.04 to 1.50 for total distance, 1.00 to 1.01 for running distance, 0.95 to 1.00 for high-speed running distance, 1.00 to 1.03 for maxi- 
U. Hasan, R. Silva, F. Clemente, Weekly variations of biomechanical load variables in soccer

mal speed distance, 0.98 to 1.03 for high accelerations distance, and 1.03 to 1.09 for players' training loads. Considering the differences in mean load between playing positions, significant differences were found for the majority of the variables, with the only exceptions being maximal speed and high accelerations distance.

The analysis of the acute weekly loads imposed on the players over the season implied greater values in the first 4 weeks of the season (pre-season) than in the following 3 weeks (weeks 5-7) by around $5000 \mathrm{~m}$ considering the overall distance covered during a week. Similarly, running distance and high-speed running distance also dropped by around 1000 and $100 \mathrm{~m}$, respectively. The larger amount of work imposed for the different variables (mainly for those associated with volume, such as total distance) during the pre-season remains in line with some descriptions provided for other contexts, which suggests that the period of the season was more dedicated to accumulate load and adjust the organism to the fundamental capacities related with aerobic capacity and resistant strength before submitting players to increases in intensity [28, 29]. After the end of the seventh week, the weekly loads were raised again and were maintained across the majority of the season, thus confirming previous works that observed limited variations of loading between mesocycles or periods of training [30].

Descriptively, the mean of total distance across the season was $5472.64 \mathrm{~m}$ per week, with a minimum of $1204.70 \mathrm{~m}$ in week 3 and a maximum of $9598.85 \mathrm{~m}$ in week 8 . The mean of running distance across the season was $523.43 \mathrm{~m}$ per week, with a minimum of $200.57 \mathrm{~m}$ in week 5 and a maximum of $1221.71 \mathrm{~m}$ in week 22. In turn, the mean of high-speed running distance across the season was $134.29 \mathrm{~m}$ per week, with a minimum of $20.02 \mathrm{~m}$ in week 23 and a maximum of $360.38 \mathrm{~m}$ in week 17 . On the other hand, the mean of maximum speed distance across the season was $25.18 \mathrm{~m}$ per week, with a minimum of $15.63 \mathrm{~m}$ in week 13 and a maximum of $31.97 \mathrm{~m}$ in week 9 , whilst the mean of high accelerations distance across the season was $25.46 \mathrm{~m}$ per week, with a minimum of $1 \mathrm{~m}$ in week 3 and a maximum of $54 \mathrm{~m}$ in week 16 .

Usually, during the pre-season (i.e., the first 4-5 weeks), per-week values vary from 40.000 to $47.000 \mathrm{~m}$ for total distance covered, from 4.000 to $5.000 \mathrm{~m}$ for running distance, and from 1.000 to $1.500 \mathrm{~m}$ for highspeed running distance [31]. Other studies [21, 32] reported values of total distance of approximately $40.000 \mathrm{~m}$ in the first 4 weeks, followed by a decrease to approximately $35.000 \mathrm{~m}$. This is in line with our study, which revealed a drop of ca. $5000 \mathrm{~m}$ from the fourth week of the pre-season. In relation to running distances and high-speed running distances during the in-season period, other studies [33, 34] showed values of approximately $6.000-7.000 \mathrm{~m}$ and $1.500-$ $2.000 \mathrm{~m}$ per week of training. Those values are slightly higher than those found in our study (i.e., ca. 3.000$4.000 \mathrm{~m}$ for running speed distance and ca. 1.000$1.200 \mathrm{~m}$ for high-speed running distance).

Regarding the variability of external load measures within weeks, a lower mean coefficient of variation (of ca. 23\% and ca. 22\%) was observed for the first and second weeks of the season for total distance covered, with more evident decreases (of ca. 10\% and ca. 16\%) in the third and twenty second weeks, respectively. For running distances, lower coefficients of variation (of ca. 13\% and ca. 19\%) were found in the third and twenty second weeks, respectively. For high-speed running, maximal speed, and high accelerations distance, a lower coefficient of variation was noted in the third week (ca. $18 \%$, ca. $7 \%$, and ca. $15 \%$ ) and in the twenty second week (ca. $19 \%$, ca. $12 \%$, and ca. $22 \%$ ). On the other hand, for player load, lower coefficients of variation were found in the third (ca. 6\%), ninth (ca. 17\%), and fifteenth (ca. 16\%) weeks. Greater coefficients of variation values were indicated in the fourth week (ca. 33\%, ca. 37\%) and the fifth week (ca. 38\%, ca. 35\%) for maximal speed distance and player load. However, all load measures remained consistent during the season.

The lower coefficient of variation values observed in the first weeks of the season show that during the pre-season, the training load undergoes limited changes within weeks, suggesting that the load may not be as linear as expected during the in-season period [21, 31]. Therefore, coaches and practitioners should consider the variability of the loads imposed on their athletes in order to pursue the training principles of progressive overload [35]. At the same time, coaches should also be aware of the progression principle, through which spike changes in weekly loads may lead to injuries, thus suggesting a weekly change of approximately $10 \%$ as a guideline [36]. Moreover, unceasing heavy training characteristics of greater monotony training values may lead to the risk of negative adaptations. Thus, it has been suggested to intersperse heavy days with easy days to impede overtraining [37].

However, the greater coefficient of variation values found in this study during the in-season period are in line with the results reported by Kelly et al. [30], who reported that the fluctuations in the internal and external load were more prominent within weeks. This variability was not observed between weeks, though, 
which means that it can be attributed to the periodization and taper strategies for promoting recovery within weekly microcycles. However, in one study [21], the within-week training load variables during the in-season period showed limited variation, revealing a high monotonous training status, which contrasts with the results of the present study. The present study revealed a lower coefficient of variation of the external load measures only in the first weeks of the season. After that, relatively consistent values of variation during the in-season period were observed, which corroborates previous studies [17, 30, 38]. A controlled variability, indeed, is positive because it promotes training adaptations and helps avoid monotony with the recovery strategies implemented within microcycles given their fluctuating nature.

The analysis of the ACWR of the players during the process revealed that the values varied in all external measures between positions. The defenders presented higher values of load (acute: 1910.6; chronic: 1748.4) in relation to the midfielders (acute: 1769; chronic: 1692.9) and the attackers (acute: 1748.2; chronic: 1696) over the 23 analysed weeks. Descriptively, the defenders presented higher values of ACWR for total distance (1.05), maximal speed distance (1.03), high accelerations distance (1.03), and player load (1.09). The midfielders and attackers presented the same values for total distance (1.04), running distance (1.01), and maximal speed distance (1.00). Meanwhile, the midfielders presented higher values for high-speed running distance (1.00) than the attackers (0.95) and defenders (0.98). Although the midfielders showed greater highspeed running distance values, this position was related to lower high accelerations distance (0.98) when compared with the defenders (1.03) and attackers (1.02).

From an injury prevention perspective, a relationship between ACWRs and injury risk has been demonstrated $[19,20,25,39,40]$. This implies the need to know more details about what may happen during a soccer season, for instance, what differences teams may expect in ACWR between positions throughout the season. Considering the workload imposed in 1 week of training relative to the average of 4 weekly workloads, Malone et al. [19] found associations between weekly workload, week-to-week workload changes, and injury risk over the season. A higher risk of injury occurrence was observed during the pre-season phase, when the weekly workloads were higher $(2984 \pm 625 \mathrm{AU})$ than those in the in-season $(2441 \pm 215 \mathrm{AU})$. This suggests that an ACWR of 1.00-1.25 is prophylactic in relation to the risk of injury, both in the pre-season and in-season periods. This is in line with our results, which revealed an overall ACWR of 0.95-1.09 over 23 weeks for all measures, considering that the weekly workloads were maintained within the 'sweet spot' zone of 0.8-1.3 [25].

Notwithstanding the aforementioned research, there is still a lack of findings regarding the profiles of ACWRs imposed on professional players in accordance with their positional roles during a soccer season. This is especially true if one considers different external load measures, which can be relevant in comprising the dynamics of a professional team. Thus, to the best of our knowledge, this is the first study to analyse the positional differences related to acute:chronic workload profiles during a season.

In analysing the differences in external load between playing positions, limited differences were found between positions within weeks for total distances. However, the defenders covered smaller total distances than the midfielders with an ES of small difference $(d=0.221)$ and attackers with a slight difference $(d=$ 0.198). Also, a greater peak coefficient of variation was noted in the midfielders (48\%) and attackers (50\%) for total distance covered, and these positions maintained higher values than the defenders throughout the season.

Moderate ES differences in running distance were found between the defenders and attackers $(d=0.610)$, and small differences were detected between the defenders and midfielders $(d=0.506)$, with the attackers covering greater distances in running speed and displaying a greater peak coefficient of variation in week 10 (53\%). However, the midfielders showed a greater coefficient of variation within and between weeks throughout the season in comparison with the defenders and midfielders.

Regarding high-speed running distance, small differences were found between the defenders and attackers $(d=0.241)$, and a slight difference was observed between the midfielders and attackers $(d=0.134)$. A greater mean coefficient of variance was noted in the midfielders and attackers (peaks of 55\% were recorded for both positions) than in the defenders throughout the season. Although significant differences were indicated for the majority of the analysed variables, no difference was found for maximal speed or high accelerations distance between positions.

These results are in line with other studies [30, 41], where limited positional differences were observed for total distances within weeks. In these studies, defenders covered greater total distances with lower within-week coefficient of variance values than midfielders and attackers. In contrast, in a study by Kelly et al. [30], 
U. Hasan, R. Silva, F. Clemente, Weekly variations of biomechanical load variables in soccer

attackers covered greater total distances than defenders, reaching distances of approximately $1387 \mathrm{~m}$. By comparison, the present study shows that the defenders reached a difference of approximately $1289 \mathrm{~m}$ in relation to the attackers and approximately $2279 \mathrm{~m}$ in relation to the midfielders. With reference to running speed and high-speed running distance, our study revealed that the defenders covered less distance than the midfielders and attackers, which is concurrent with other studies [21, 42].

Regarding the limited variations in external load between the first 4 weeks of the pre-season and during the in-season period, the differences observed between positions within weeks in the present study were evident, as was also reported by Malone et al. [21]. This finding supports the variability existing between different player roles in each microcycle, which can be attributed to the unpredictable, dynamic, and complex nature of soccer, as well as to the ideologies of coaches and their wisdom regarding strategies for promoting training adaptations within their teams [41, 43].

This study contained some limitations. First, the sample was limited to 1 elite soccer team. Another limitation was that we considered only external load measures and did not involve internal load measures (e.g., s-RPE and heart rate). Finally, owing to the limited number of players, this study only grouped participants into defenders, midfielders, and attackers. Future studies should comprise a larger sample (more teams), as well as include internal load measures and more playing positions.

Despite the limitations of the present study, to the best of our knowledge, this is the first research work to present ACWR profiles of various external measures and the differences among playing positions. Thus, the study provides useful information relating to the training loads of an elite soccer team from the First Portuguese League (Europe) throughout a season. This work also demonstrates ACWR differences between playing positions for various measures that can be extracted from GPS devices, thus providing some descriptive values that can help coaches to understand the typical values in this type of population.

Some practical implications may arise from the study. One of them is the need to properly monitor the training load by positioning, namely considering the individual need with regard to the workload in a match. Possibly, an increase in the individualization of training may also benefit the control of load management. Moreover, bearing in mind the inter-week variability, it is recommended to identify specific monitoring procedures that may help coaches to manage the load in a progressive way, aiming to decrease the huge variability between weeks that may expose players to higher injury risks.

\section{Conclusions}

This study described weekly variations of acute external load measures during a soccer season. The results revealed that the variables associated with volume were greater during the pre-season than during the season. Considering the variability of external load measures within weeks, the overall results indicated a lower coefficient of variation for the external measures in the pre-season when compared with the inseason phase. As for the players' ACWR, it was postulated that the defenders presented higher values of ACWR than the midfielders and attackers. Finally, it was implied that the attackers covered greater running distances and exhibited more high-speed running than the defenders and midfielders, though no differences were found between positions for maximal speed or high accelerations distances.

\section{Acknowledgments}

This study made part of one curricular unit of Master in Sports Training at Escola Superior de Desporto e Lazer, Instituto Politécnico de Viana do Castelo, Portugal.

\section{Disclosure statement}

No author has any financial interest or received any financial benefit from this research.

\section{Conflict of interest}

The authors state no conflict of interest.

\section{References}

1. Gabbett TJ, Nassis GP, Oetter E, Pretorius J, Johnston N, Medina D, et al. The athlete monitoring cycle: a practical guide to interpreting and applying training monitoring data. Br J Sports Med. 2017;51(20):14511452; doi: 10.1136/bjsports-2016-097298.

2. Lambert MI, Borresen J. Measuring training load in sports. Int J Sports Physiol Perform. 2010;5(3):406-411; doi: 10.1123/ijspp.5.3.406.

3. Halson SL. Monitoring training load to understand fatigue in athletes. Sports Med. 2014;44(Suppl. 2):139147; doi: 10.1007/s40279-014-0253-z.

4. Bourdon PC, Cardinale M, Murray A, Gastin P, Kellmann M, Varley MC, et al. Monitoring athlete training loads: consensus statement. Int J Sports Physiol Perform. 2017;12(Suppl. 2):S2-161-S2-170; doi: 10.1123/ IJSPP.2017-0208. 
5. Carling C, Bradley P, McCall A, Dupont G. Match-tomatch variability in high-speed running activity in a professional soccer team. J Sports Sci. 2016;34(24):22152223; doi: 10.1080/02640414.2016.1176228.

6. Hoppe MW, Baumgart C, Slomka M, Polglaze T, Freiwald J. Variability of metabolic power data in elite soccer players during pre-season matches. J Hum Kinet. 2017;58(1):233-245; doi: 10.1515/hukin-2017-0083.

7. Jeong T-S, Reilly T, Morton J, Bae S-W, Drust B. Quantification of the physiological loading of one week of "pre-season" and one week of "in-season" training in professional soccer players. J Sports Sci. 2011;29(11): 1161-1166; doi: 10.1080/02640414.2011.583671.

8. Clemente FM, Rabbani A, Ferreira R, Araújo JP. Drops in physical performance during intermittent small-sided and conditioned games in professional soccer players. Hum Mov. 2020;21(1):7-14; doi: 10.5114/hm.2020.88148.

9. Clemente FM, Sarmento H. The effects of small-sided soccer games on technical actions and skills: a systematic review. Hum Mov. 2020;21(3):100-119; doi: 10.5114/ hm.2020.93014.

10. Castellano J, Blanco-Villaseñor A, Álvarez D. Contextual variables and time-motion analysis in soccer. Int $\mathrm{J}$ SportsMed.2011;32(6):415-421; doi:10.1055/s-00311271771.

11. Santos PM, Lago-Penas C. Defensive positioning on the pitch in relation with situational variables of a professional football team during regaining possession. Hum Mov. 2019;20(2):50-56; doi: 10.5114/hm.2019.81019.

12. Lacome M, Simpson BM, Cholley Y, Lambert P, Buchheit M. Small-sided games in elite soccer: does one size fit all? Int J Sports Physiol Perform. 2018;13(5):568576; doi: 10.1123/ijspp.2017-0214.

13. Clemente FM. The threats of small-sided soccer games: a discussion about their differences with the match external load demands and their variability levels. Strength Cond J; doi: 10.1519/SSC.0000000000000526.

14. Clemente FM, Rabbani A, Conte D, Castillo D, Afonso J, Truman Clark CC, et al. Training/match external load ratios in professional soccer players: a full-season study. Int J Environ Res Public Health. 2019;16(17):3057; doi: 10.3390/ijerph16173057.

15. Paul DJ, Bradley PS, Nassis GP. Factors affecting match running performance of elite soccer players: shedding some light on the complexity. Int J Sports Physiol Perform. 2015;10(4):516-519; doi: 10.1123/IJSPP.20150029.

16. Rago V, Silva JR, Mohr M, Barreira D, Krustrup P, Rebelo AN. Variability of activity profile during mediumsided games in professional soccer. J Sports Med Phys Fitness. 2019;59(4):547-554; doi: 10.23736/S00224707.18.08376-7.

17. Clemente FM, Rabbani A, Kargarfard M, Nikolaidis PT, Rosemann T, Knechtle B. Session-to-session variations of external load measures of youth soccer players in medium-sided games. Int J Environ Res Public Health. 2019;16(19):3612; doi: 10.3390/ijerph16193612.
18. Clemente FM, Silva AF, Clark CCT, Conte D, Ribeiro J, Mendes B, et al. Analyzing the seasonal changes and relationships in training load and wellness in elite volleyball players. Int J Sports Physiol Perform. 2020; 15(5):731-740; doi: 10.1123/ijspp.2019-0251.

19. Malone S, Owen A, Newton M, Mendes B, Collins KD, Gabbett TJ. The acute:chronic workload ratio in relation to injury risk in professional soccer. J Sci Med Sport. 2017;20(6):561-565; doi:10.1016/j.jsams.2016.10.014.

20. Hulin BT, Gabbett TJ, Blanch P, Chapman P, Bailey D, Orchard JW. Spikes in acute workload are associated with increased injury risk in elite cricket fast bowlers. Br J Sports Med. 2014;48(8):708-712; doi: 10.1136/ bjsports-2013-092524.

21. Malone JJ, Di Michele R, Morgans R, Burgess D, Morton JP, Drust B. Seasonal training-load quantification in elite English Premier League soccer players. Int J Sports Physiol Perform. 2015;10(4):489-497; doi: 10.1123/ ijspp.2014-0352.

22. Dalen T, Ingebrigtsen J, Ettema G, Hjelde GH, Wisløff U. Player load, acceleration, and deceleration during fortyfive competitive matches of elite soccer. J Strength Cond Res. 2016;30(2):351-359; doi: 10.1519/JSC.0000000 000001063.

23. Baptista I, Johansen D, Figueiredo P, Rebelo A, Pettersen SA. Positional differences in peak- and accumulated-training load relative to match load in elite football. Sports. 2019;8(1):1; doi: 10.3390/sports8010001.

24. Nikolaidis PT, Clemente FM, van der Linden CMI, Rosemann T, Knechtle B. Validity and reliability of $10-\mathrm{Hz}$ global positioning system to assess in-line movement and change of direction. Front Physiol. 2018;9:228; doi: 10.3389/fphys.2018.00228.

25. Gabbett TJ. The training-injury prevention paradox: should athletes be training smarter and harder? Br J Sports Med. 2016;50(5):273-280; doi: 10.1136/bjsports-2015-095788.

26. Cohen J. Statistical power analysis for the behavioral sciences, $2^{\text {nd }}$ ed. New York: Routledge; 2013.

27. Batterham AM, Hopkins WG. Making meaningful inferences about magnitudes. Int J Sports Physiol Perform. 2006;1(1):50-57; doi: 10.1123/ijspp.1.1.50.

28. Fessi MS, Nouira S, Dellal A, Owen A, Elloumi M, Moalla W. Changes of the psychophysical state and feeling of wellness of professional soccer players during pre-season and in-season periods. Res Sports Med. 2016;24(4):375-386; doi: 10.1080/15438627.2016.12 22278.

29. Clemente FM, Clark C, Castillo D, Sarmento H, Nikolaidis PT, Rosemann T, et al. Variations of training load, monotony, and strain and dose-response relationships with maximal aerobic speed, maximal oxygen uptake, and isokinetic strength in professional soccer players. PLoS One. 2019;14(12):e0225522; doi: 10.1371/journal.pone.0225522.

30. Kelly DM, Strudwick AJ, Atkinson G, Drust B, Gregson W. Quantification of training and match-load dis- 


\section{HUMAN MOVEMENT}

U. Hasan, R. Silva, F. Clemente, Weekly variations of biomechanical load variables in soccer

tribution across a season in elite English Premier League soccer players. Sci Med Football. 2020;4(1):59-67; doi: 10.1080/24733938.2019.1651934.

31. Clemente FM, Seerden G, van der Linden CMI. Quantifying the physical loading of five weeks of pre-season training in professional soccer teams from Dutch and Portuguese leagues. Physiol Behav. 2019;209:112588; doi: 10.1016/j.physbeh.2019.112588.

32. Djaoui L, Wong DP, Pialoux V, Hautier C, Da Silva CD, Chamari K, et al. Physical activity during a prolonged congested period in a top-class European football team. Asian J Sports Med. 2014;5(1):47-53; doi: 10.5812/ asjsm.34233.

33. Gaudino P, Iaia FM, Alberti G, Strudwick AJ, Atkinson G, Gregson W. Monitoring training in elite soccer players: systematic bias between running speed and metabolic power data. Int J Sports Med. 2013;34(11): 963-968; doi: 10.1055/s-0033-1337943.

34. Oliveira R, Brito JP, Martins A, Mendes B, Marinho DA, Ferraz R, et al. In-season internal and external training load quantification of an elite European soccer team. PLoS One. 2019;14(4):e0209393; doi: 10.1371/journal.pone.0209393.

35. Powers SK, Howley ET. Exercise physiology: theory and application to fitness and performance, $9^{\text {th }} \mathrm{ed}$. New York: McGraw-Hill Education; 2014.

36. Gabbett TJ. Debunking the myths about training load, injury and performance: empirical evidence, hot topics and recommendations for practitioners. $\mathrm{Br} \mathrm{J}$ Sports Med. 2020;54(1):58-66; doi: 10.1136/bjsports-2018099784.

37. Foster C. Monitoring training in athletes with reference to overtraining syndrome. Med Sci Sports Exerc. 1998;30(7):1164-1168; doi: 10.1097/00005768-1998 07000-00023.

38. Owen AL, Lago-Penñs C, Gómez MÁ, Mendes B, Dellal A. Analysis of a training mesocycle and positional quantification in elite European soccer players. Int J Sports Sci Coach. 2017;12(5):665-676; doi: 10.1177/ 1747954117727851.

39. Enright K, Green M, Hay G, Malone JJ. Workload and injury in professional soccer players: role of injury tissue type and injury severity. Int J Sports Med. 2020;41(2): 89-97; doi: 10.1055/a-0997-6741.

40. Bowen L, Gross AS, Gimpel M, Bruce-Low S, Li FX. Spikes in acute:chronic workload ratio (ACWR) associated with a 5-7 times greater injury rate in English Premier League football players: a comprehensive 3-year study. Br J Sports Med. 2020;54(12):731-738; doi: 10.1136/bjsports-2018-099422.

41. Martín-García A, Gómez Díaz A, Bradley PS, Morera F, Casamichana D. Quantification of a professional football team's external load using a microcycle structure. J Strength Cond Res. 2018;32(12):3511-3518; doi: 10.1519/JSC.0000000000002816.

42. Dellal A, Wong DP, Moalla W, Chamari K. Physical and technical activity of soccer players in the French First
League - with special reference to their playing position. Int SportMed J. 2010;11(2):278-290.

43. Bradley PS, Carling C, Archer D, Roberts J, Dodds A, Di Mascio M, et al. The effect of playing formation on high-intensity running and technical profiles in English FA Premier League soccer matches. J Sports Sci. 2011; 29(8):821-830; doi: 10.1080/02640414.2011.561868. 